\title{
Rev is necessary for translation but not cytoplasmic accumulation of HIV-1 vif, vpr, and env/vpu 2 RNAs
}

\author{
Salvatore J. Arrigo ${ }^{1}$ and Irvin S.Y. Chen \\ Departments of Microbiology and Immunology and Medicine, University of California at Los Angeles School of Medicine \\ and Jonsson Comprehensive Cancer Center, Los Angeles, California 90024 USA
}

\begin{abstract}
The effect of Rev on cytoplasmic accumulation of the singly spliced human immunodeficiency virus type 1 (HIV-1) vif, vpr, and env/vpu RNAs was examined by using a quantitative RNA polymerase chain reaction (PCR) analysis following transfection of complete proviral molecular clones into lymphoid cells. Previously published studies using subgenomic env constructs in nonlymphoid cell types concluded that Rev was necessary for cytoplasmic accumulation of high levels of unspliced env RNA and that, by analogy, Rev must be necessary for the cytoplasmic accumulation of all HIV-1 RNAs that contain the Rev-responsive element (RRE). We confirm those results in COS cells. Unexpectedly, in lymphoid cells, we find that although Rev acts somewhat to increase the cytoplasmic level of full-length HIV-1 RNA, Rev has little or no effect on cytoplasmic accumulation of singly spliced HIV-1 RNAs. However, Env protein expression was greatly reduced in the absence of Rev. Analysis of the cytoplasmic RNA revealed that in the absence of Rev or the RRE, the cytoplasmic vif, vpr, and env/vpu 2 RNAs were not associated with polysomes but with a complex of $40 \mathrm{~S}-80 \mathrm{~S}$ in size. Consequently, efficient expression of the Vif, Vpr, Vpu, and Env proteins from these RNAs is dependent on Rev. These results exclude a mechanism whereby the sole function of Rev is simply to export RNAs from nucleus to cytoplasm. We discuss other models to take into account the dependence on Rev for efficient translation of cytoplasmic HIV-1 RNAs.
\end{abstract}

[Key Words: Rev; HIV-1; cytoplasmic accumulation; RNA; translation]

Received November 26, 1990; revised version accepted February 19, 1991.

Human immunodeficiency virus type 1 (HIV-1) encodes a large number of structural and regulatory genes within a relatively small genome (Gallo et al. 1988). It accomplishes this through a complex arrangement of genes encoded in overlapping reading frames and expresses these genes through elaborate splicing of a single mRNA precursor molecule (Arya et al. 1985; Muesing et al. 1985; Rabson et al. 1985; Strebel et al. 1987; Ahmad and Venkatesan 1988; Sadaie et al. 1988b; Arrigo et al. 1990). This precursor RNA serves two additional roles as viral genomic RNA and gag/pol mRNA. Control over the expression of these genes is accomplished in part by the regulatory proteins of HIV-1, Tat, and Rev. Tat seems to function to increase both transcription and translation of DNA and RNAs containing the trans-acting response element (Rosen et al. 1985, 1986; Sodroski et al. 1985; Cullen 1986; Dayton et al. 1986; Peterlin et al. 1986; Wright et al. 1986; Muesing et al. 1987; Le et al. 1988). Rev has also been shown to be necessary for HIV-1 viral replication (Feinberg et al. 1986; Sodroski et al. 1986;

'Present address: Department of Microbiology and Immunology, Medical University of South Carolina, Charleston, South Carolina 29425 USA.
Terwilliger et al. 1988). Proviral constructs were used to determine the effect of Rev on viral gene expression (Sodroski et al. 1986; Sadaie et al. 1988a; Arrigo et al. 1989; Felber et al. 1989; Hadzopoulou-Cladaras et al. 1989|. Rev and the Rev-responsive element (RRE) were shown to be required for high-level expression of viral Gag and Env structural proteins (Sodroski et al. 1986; Sadaie et al. 1988a; Hadzopoulou-Cladaras et al. 1989), as well as for expression of high levels of secreted Gag p24 protein (Arrigo et al. 1989; Malim et al. 1989a). Rev has also been shown to be necessary for cytoplasmic accumulation of wild-type levels of HIV-1 unspliced full-length RNA (Arrigo et al. 1989; Felber et al. 1989), and it concomitantly decreases the level of HIV-1 tat/rev and nef RNAs (Arrigo et al. 1989).

The current major hypothesis concerning regulation of HIV-1 gene expression by Rev is that Rev facilitates transport of unspliced and singly spliced RNAs from the nucleus to the cytoplasm. This hypothesis is supported mainly by reports in which the effect of Rev was examined by using subgenomic env constructs that express env as an unspliced RNA in nonlymphoid cell lines (Knight et al. 1987; Malim et al. 1988, 1989b; Rosen et al. 1988; Emerman et al. 1989; Hadzopoulou-Cladaras et al. 
1989; Hammarskjold et al. 1989); in some cases, it was capable of being spliced further to a tat RNA (Malim et al. 1988, 1989b; Rosen et al. 1988; Hammarskjold et al. 1989). Rev was shown to be necessary for accumulation of high levels of cytoplasmic unspliced env RNA (Malim et al. 1989) and dependent on cis-acting sequences within env, termed the RRE (Emerman et al. 1989; Hammarskjold et al. 1989; Malim et al. 1989b). In one case, a corresponding nuclear accumulation of unspliced env RNA was demonstrated (Hammarskjold et al. 1989). Examination of unfractionated whole-cell RNA showed that the total cellular level of unspliced env RNA was not significantly altered (Emerman et al. 1989; Hammarskjold et al. 1989; Malim et al. 1989b). This suggested that Rev acted by altering the nuclear/cytoplasmic distribution of unspliced env RNA by allowing its export to the cytoplasm. However, one report demonstrated a 15fold increase in the level of total cellular unspliced env RNA in the presence of Rev (Hadzopoulou-Cladaras et al. 1989). Negative-acting sequences, termed cis-acting regulatory sequences (CRS), have been proposed to be present within the unspliced and singly spliced RNAs and to interfere with the cytoplasmic accumulation of these RNAs (Rosen et al. 1988; Emerman et al. 1989).

Because the vif, vpr, and env/vpu RNAs of HIV-1 contain the CRS and RRE sequences, they have been proposed to be dependent on Rev and the RRE for cytoplasmic accumulation when expressed in the context of an intact proviral construct. We directly examined the effect of Rev on the levels of nuclear and cytoplasmic vif, $v p r$, and env/vpu 2 RNAs expressed from proviral constructs. We demonstrate that in lymphoid cells, in contrast to COS cells, the cytoplasmic levels of these singly spliced RNAs are unaltered by Rev. No detectable structural proteins are expressed in the absence of Rev or the RRE in lymphoid cells. We show further that the basis for the failure of these RNAs to express protein can be attributed to the fact that they are not associated with polysomes in the absence of Rev or the RRE. Therefore, a simple theory for $\mathrm{Rev}$ as a facilitator of transport of RNAs from nucleus to cytoplasm is unlikely.

\section{Results}

Rev modulates the cytoplasmic accumulation of env/vpu 2 RNA in COS cells

Previously published reports showed that Rev regulated the level of env RNA and protein expressed from the subgenomic constructs in COS cells. It was concluded from these studies that Rev was necessary for cytoplasmic accumulation of singly spliced HIV-1 RNAs. We wished to determine whether this regulation actually occurred when env was expressed as a singly spliced RNA from an intact proviral construct. rev and wild-type constructs (Fig. 1A) were electroporated into COS cells, and nuclear and cytoplasmic RNAs were prepared by standard nonionic detergent lysis methods at $48 \mathrm{hr}$ postelectroporation. Because Rev and the RRE appear to be necessary for structural protein expression, supernatant Gag p24 levels were assayed to determine the level of secreted p24 in each transfection (Table 1, experiment 1). In agreement with previous results, wild type expressed $>750$-fold, as much Gag p24 supernatant as the rev ${ }^{-}$ mutant. Polymerase chain reaction (PCR) analysis for RNA was performed on cell equivalents of nuclear and cytoplasmic RNA with oligonucleotide primer pairs specific for HIV-1 RNAs (Fig. 1A). Consistent with predictions from previous studies using subgenomic constructs, the level of cytoplasmic full-length HIV-1 RNA was reduced dramatically with the $\mathrm{rev}^{-}$mutant, relative to wild type (Fig. 2). The $\mathrm{rev}^{-}$mutant demonstrated a predominantly nuclear localization of full-length HIV-1 RNA. Cytoplasmic levels of env/vpu 2 RNAs were also reduced in the mutant relative to wild type, but equivalent levels were apparent in the nucleus. tat/rev RNA was predominantly cytoplasmic, and higher with the $\mathrm{reV}^{-}$mutant in both nuclear and cytoplasmic fractions. To control for the quality of the fractionation procedure, RNA PCR analysis specific for unspliced human thymidine kinase pre-mRNA was performed (Fig. 2). The murine homolog of this pre-mRNA has been detected previously, predominantly in the nuclear but not cytoplasmic fraction of cultured murine fibroblasts (Gudas et al. 1988). The oligonucleotide primer pairs used in this PCR (Fig. 1B) work well in RNA PCR analysis on RNA from both monkey and human cell lines, as well as on RNA from human peripheral blood lymphocytes $(\mathrm{PBL}$; data not shown). Relative to the nuclear fractions, low levels of thymidine kinase pre-mRNA are seen in the cytoplasmic fractions, indicating a good separation of nuclear and cytoplasmic fractions. Similar signals in the nuclear fractions of wild type and mutants indicate equivalent recoveries of nuclear RNA. [These samples had been treated previously with RNase-free DNase and did not give a detectable signal for thymidine kinase DNA in the same PCR (data not shown).] Therefore, in COS cells, Rev is necessary for the cytoplasmic accumulation of high levels of both unspliced full-length HIV-1 RNA and singly spliced env RNA.

Rev does not affect the cytoplasmic levels of vif, vpr, and env/vpu 2 RNAs in lymphoid cells

Similar experiments to those shown in COS cells were performed in lymphoid cells. The 729 cell line was electroporated with mutant and wild-type constructs (Fig. 1). To evaluate the nuclear/cytoplasmic fractionation in lymphoid cells, we analyzed the nucleic acids prepared by nonionic detergent lysis $48 \mathrm{hr}$ postelectroporation by using agarose gel electrophoresis in the presence of ethidium bromide (Fig. 3A). The genomic DNA and the $45 \mathrm{~S}$ and $32 \mathrm{~S}$ rRNA precursors were detectable only in the nuclear fraction. The bulk of the $28 \mathrm{~S}$ and $18 \mathrm{~S}$ rRNAs and tRNAs were found in the cytoplasmic fractions. The major DNA and RNA components of nuclear and cytoplasmic fractions appeared to be separated appropriately by this fractionation procedure.

Nuclear and cytoplasmic RNA was prepared from 729 cells electroporated with wild-type and mutant con- 


\section{Arrigo and Chen}
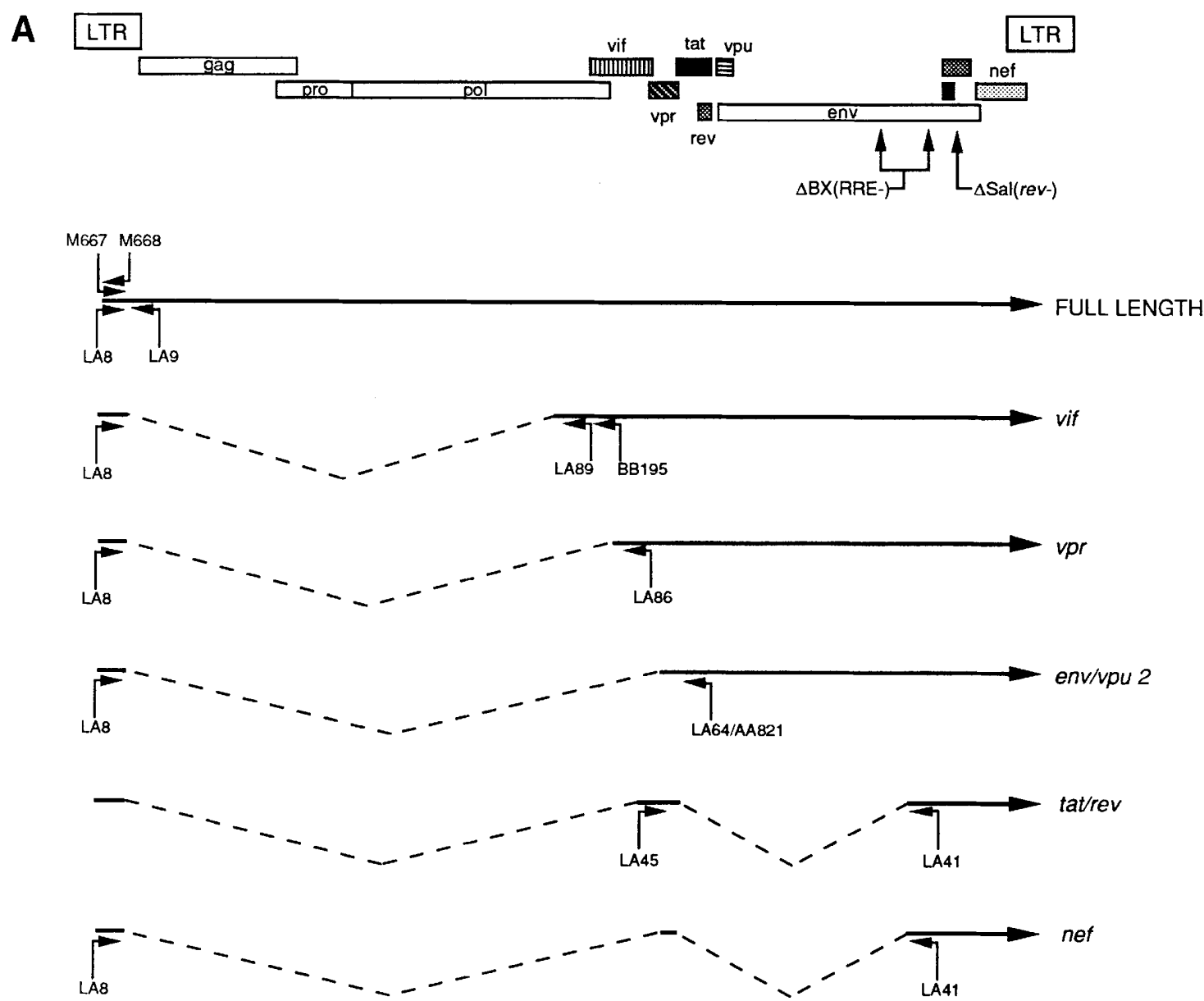

B
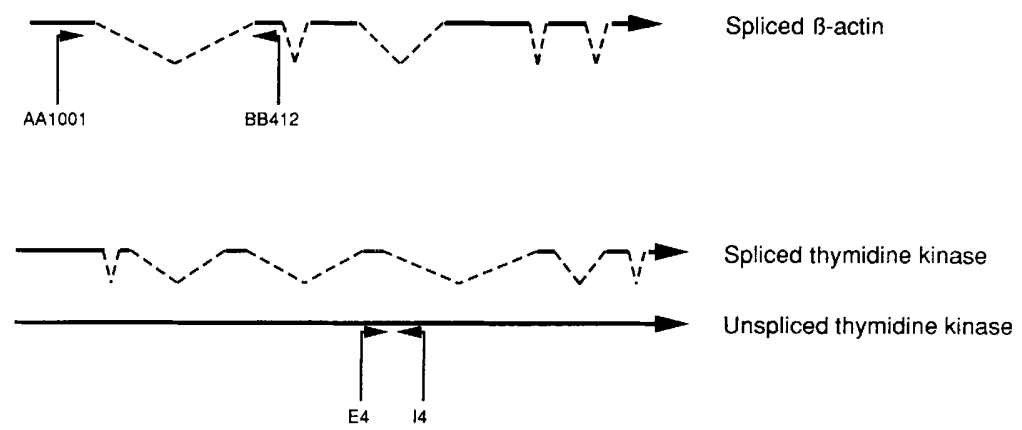

Figure 1. Oligonucleotide primer pairs used in RNA PCR analysis. (A) Schematic representation of HIV-1 genome and RNA species. The locations of the $\Delta \mathrm{BX}$ and $\Delta$ Sal mutants are indicated, and the location and orientation of each set of oligonucleotide primer pairs used to detect the various HIV-1 RNAs are shown beneath each RNA. The oligonucleotide primer pair M667/M668 is homologous to sequences present in the $5^{\prime}$ leader of all HIV-l RNAs. $(B)$ Schematic representation of $\beta$-actin and thymidine kinase RNAs. The location and orientation of each set of oligonucleotide primer pairs used to detect spliced $\beta$-actin RNA and unspliced thymidine kinase pre-mRNA are shown beneath each RNA.

structs. Cell equivalents of RNA were used in RNA PCR analysis to allow direct comparison of results. A dose response of cell RNA was included to provide a standard curve for quantitation of results. Oligonucleotide primer pairs specific for unspliced thymidine kinase pre-mRNA (Fig. 1B) were employed to assess the quality of the fractionation procedure. Similar to the COS cell fractionations, the vast majority of the unspliced thymidine ki- nase pre-mRNA was found in the nuclear fractions (Fig. 3B). Therefore, in both cell types, leakage of nuclear premRNA into the cytoplasmic fraction appeared to be minimal. Thymidine kinase also serves as a measure of RNA recovery; note that the $\mathrm{Rev}^{-}$mutant has relatively less RNA in the nuclear fraction. In addition to thymidine kinase, other control assays were performed to assess transfection efficiency and RNA recovery. RNA PCR 
Table 1. Production of Gag p24 from electroporated cells

\begin{tabular}{|c|c|c|c|c|c|c|}
\hline \multirow[b]{3}{*}{ Construct } & \multicolumn{6}{|c|}{ Amount of Gag p24 $(\mathrm{pg} / \mathrm{ml})^{\mathrm{a}}$ produced in } \\
\hline & \multirow{2}{*}{$\begin{array}{l}\text { exp. } 1^{b} \\
\text { (COS) } \\
\text { supnt }\end{array}$} & \multicolumn{2}{|c|}{$\begin{array}{c}\text { exp. } 2 \\
(729)\end{array}$} & \multirow{2}{*}{$\begin{array}{l}\exp .3^{c} \\
(729) \\
\text { supnt }\end{array}$} & \multirow{2}{*}{$\begin{array}{l}\text { exp. } 4^{d} \\
(729) \\
\text { supnt }\end{array}$} & \multirow{2}{*}{$\begin{array}{l}\text { exp. } 5^{e} \\
(729) \\
\text { supnt }\end{array}$} \\
\hline & & cyto & supnt & & & \\
\hline$\Delta \mathrm{BX}\left(\mathrm{RRE}^{-}\right)$ & NT & $<20$ & $<20$ & 309 & NT & NT \\
\hline$\Delta$ Sal $\left(\mathrm{rev}^{-}\right)$ & NT & $<20$ & $<20$ & $<20$ & NT & NT \\
\hline pYKJRCSF (wt) & NT & 2300 & 9400 & $>145,000$ & NT & NT \\
\hline$\triangle \mathrm{BX} / \mathrm{EBV}^{-}\left(\mathrm{RRE}^{-}\right)$ & NT & $<20$ & $<20$ & NT & 101 & $<20$ \\
\hline$\Delta \mathrm{BX} / \mathrm{EBV}^{+}\left(\mathrm{RRE}^{-}\right)$ & NT & $<20$ & $<20$ & NT & NT & NT \\
\hline$\Delta \mathrm{Sal} / \mathrm{EBV}^{-}\left(\mathrm{reV}^{-}\right)$ & NT & $<20$ & $<20$ & NT & 178 & $<20$ \\
\hline$\Delta \mathrm{Sal} / \mathrm{EBV}^{+}\left(\mathrm{rev}^{-}\right)$ & 649 & $<20$ & $<20$ & NT & NT & NT \\
\hline pYKJRCSF/EBV ${ }^{-}(w t)$ & NT & 6500 & 35,000 & NT & 156,000 & 97,000 \\
\hline pYKJRCSF/EBV ${ }^{+}(w t)$ & 506,000 & 7400 & 42,000 & NT & NT & NT \\
\hline
\end{tabular}

Abbreviations: (COS) monkey kidney fibroblast cell line transformed by simian virus $40 ;(729)$ human lympoid cell line transformed by $\mathrm{EBV}_{i}$ (supnt) supernatant; (cyto) cytoplasmic lysates; (NT) not tested; $\left(\right.$ wt) wild-type; $\left(\mathrm{EBV}^{+} / \mathrm{EBV}^{-}\right) \mathrm{The}^{-}$presence and orientation of the EBV OriP in the construct.

Culture supernatants from cells (COS or 729) transfected with $50 \mu \mathrm{g}$ of the indicated constructs for each $10^{7}$ cells in $10 \mathrm{ml}$ of media were assayed at $48 \mathrm{hr}$ post-transfection. Cytoplasmic lysates were diluted to $10^{7}$ cell equivalents in $10 \mathrm{ml}$ prior to ELISA.

${ }^{a}$ Detected by ELISA (Abbott Laboratories). Values $<20$ are below the sensitivity of this assay.

${ }^{b}$ Results from the same experiment used for nuclear/cytoplasmic RNA analysis shown in Fig. 2.

${ }^{c}$ Results from same experiment used for nuclear/cytoplasmic RNA analysis shown in Fig. 3B and C.

${ }^{\mathrm{d}}$ Results from same experiment used for immunoprecipitation analysis shown in Fig. 4.

${ }^{\text {e}}$ Results from same experiment used for both RNA size fractionation shown in Fig. 5 and polysomal RNA analysis shown in Fig. 6B.

analysis using oligonucleotide primers specific for a coelectroporated CMV-neo construct, which expresses a neomycin-resistance gene RNA from the cytomegalovirus immediate early promoter, showed that the electroporation efficiency and cytoplasmic RNA recovery for each construct was similar in this experiment (Fig. 3C).

Quantitative PCR analysis for RNA was performed on the same fractionated cells as in Figure 3B, by using oligonucleotide primer pairs specific for the various HIV-1 RNAs. Cell equivalents of RNA were used to allow direct comparison of the levels of nuclear and cytoplasmic RNAs. The locations of each of the oligonucleotide primers used in detection of specific HIV-1 RNAs are shown in Figure 1A. Threefold sequential dilutions of HIV-1-infected or -transfected cell RNA were included to provide a quantitative dose response of input RNA. Analysis of total HIV-1 RNA, using oligonucleotide primers homologous to the $5^{\prime}$ leader sequence present in all HIV RNAs, indicated that $>90 \%$ of HIV-1 RNA was cytoplasmic and that the relative levels of total HIV-1 RNA expressed from mutant and wild-type proviral constructs were similar (Fig. 3C). Low levels of HIV-1 RNA can be seen in all nuclear samples in a longer exposure (data not shown). In other experiments, the distribution of RNA between nuclear and cytoplasmic fractions was somewhat variable; however, the total amount of HIV-1 RNA was similar for wild type and mutants within each fraction (data not shown).

Examination of the same fractions with probes designed to detect singly spliced HIV-1 RNAs (Arrigo et al. 1990) revealed marked differences from COS cells. More than $90 \%$ of the env/vpu 2 RNA was found in the cyto- plasmic fractions of both mutants and wild type. This is in contrast to the fractionation of thymidine kinase premRNA, which showed a predominantly nuclear localization with the same RNA samples. Cytoplasmic levels of env/vpu 2 RNAs appeared to be unchanged between the wild type and mutants (Fig. 3C), unlike in COS cells, where cytoplasmic levels of $e n v / v p u 2$ were lower in the $\mathrm{rev}^{-}$mutant. vif and vpr RNAs gave similar results. No significant difference in singly spliced cytoplasmic RNA levels was seen between mutant and wild-type constructs in multiple experiments over a wide range of total levels of RNA expression from the proviral constructs (data not shown).

As our previous results indicated a difference in cytoplasmic levels of full-length HIV-1 RNAs in the presence or absence of Rev, we re-examined full-length HIV-1 RNA in this experiment (Arrigo et al. 1989). As in previous results, cytoplasmic level of full-length HIV-1 RNA was decreased $\sim 10$-fold with the mutants relative to wild type. The cytoplasmic level of tat/rev RNA was concomitantly increased $\sim 10$-fold with the $\mathrm{rev}^{-}$and $\mathrm{RRE}^{-}$mutants relative to wild type (Arrigo et al. 1989). The majority of both gag/pol and tat/rev RNAs was found in the cytoplasmic fractions with both mutants and wild type. It is noteworthy that although the cytoplasmic level of HIV-1 full-length gag/pol RNA was reduced 10-fold with the mutants, a significant level of cytoplasmic RNA was still detectable. The reduction in the level of secreted Gag p24 in the culture media was more severe than the reduction in cytoplasmic $\mathrm{gag} / \mathrm{pol}$ RNA, demonstrating a reduction of $>450$-fold with the mutants (Table 1, experiment 3 ). In all experiments per- 


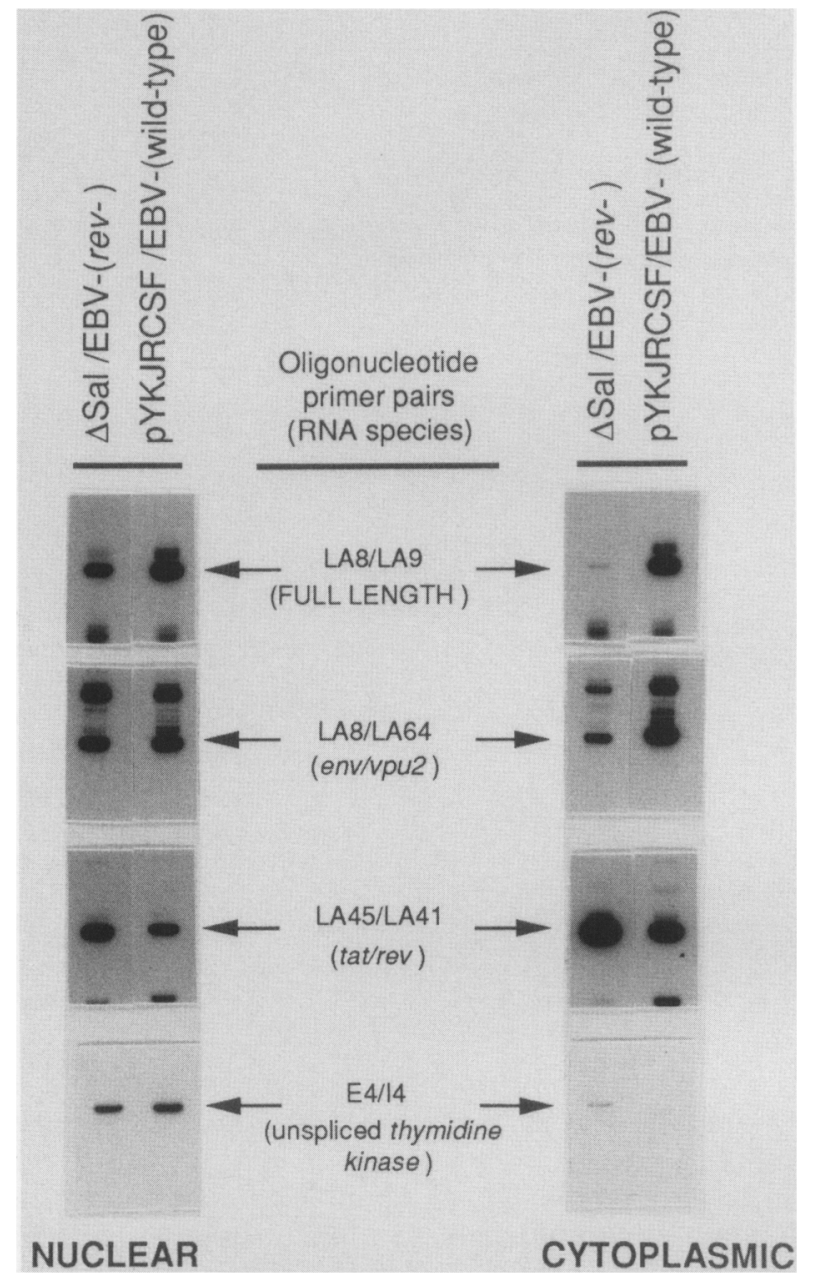

Figure 2. Analysis of the effect of Rev on nuclear and cytoplasmic levels of HIV-1 RNAs in COS cells. Results of RNA PCR and lysis, using the designated oligonucleotide primer pairs. Nuclear and cytoplasmic RNA were prepared from $10^{7} \mathrm{COS}$ cells electroporated with $50 \mu \mathrm{g}$ of the indicated proviral constructs. RNA PCR was performed on cell equivalents of nuclear or cytoplasmic RNA, as described (Arrigo et al. 1990).

formed, we observed a disparity between the level of cytoplasmic full-length $\mathrm{gag} / \mathrm{pol}$ RNA and the level of Gag p24 production (data not shown).

Therefore, these results demonstrate that in lymphoid cells, the presence of Rev is not necessary for the cytoplasmic accumulation of the singly spliced vif, vpr, and env/vpu 2 RNAs. Rev does affect the extent of cytoplasmic accumulation of unspliced gag/pol RNA; however, this effect is not sufficient to account for the almost total absence of detectable Gag p24 protein in the mutants.

\section{Rev is necessary for accumulation of Env and Gag proteins}

Previous studies had shown that Rev and the RRE are required for expression of high levels of HIV-1 Gag and Env proteins. Because we did not detect any differences in the level of cytoplasmic env RNA, we wished to de- termine the effect of Rev on levels of Env and Gag proteins in this experimental system. The 729 B-cell line was electroporated with wild-type and mutant constructs and labeled with $\left[{ }^{35} \mathrm{~S}\right]$ methionine and $\left[{ }^{35} \mathrm{~S}\right]$ cysteine. Lysates from these cells were immunoprecipitated with pooled human anti-HIV serum. The results are shown in Figure 4. Although high levels of Gag p24 and p 55 could be seen with the wild type, no detectable Gag p24 or p55 was seen with the mutants. This was in good agreement with p24 enzyme-linked immunosorbent assay (ELISA) data of supernatant p24 levels from these cells showing a difference of $>800$-fold between the wild type and mutants assayed $48 \mathrm{hr}$ postelectroporation (Table 1, experiment 4). Intracellular Gag p24 is similarly reduced, as measured by ELISA, with the mutants (Table 1, experiment 2). Similar results were seen in other experiments (Table 1). Although a high level of Env gp160/gp120 could be seen with the wild type, no detectable gp160/gp120 Env was seen in the mutants. Two bands, migrating between 21.5 and $30 \mathrm{kD}$, not seen with the control or wild-type construct, were detected with both mutant constructs. These two bands represent Nef and were specifically immunoprecipitated with $\alpha$-Nef antibodies (data not shown). This is consistent with previous RNA data showing an increase in nef RNA with the mutants (Arrigo et al. 1989), as well as with a previous report demonstrating an increase in Nef with a $\mathrm{reV}^{-}$mutant (Ahmad et al. 1989). In agreement with previous studies, these results indicate that Rev is necessary for accumulation of Gag and Env proteins.

The sizes of vif, vpr, and env/vpu 2 RNAs are not altered by $\mathrm{Rev}$

It was formally a possibility that the absence of Rev or the RRE might lead to aberrant splicing of the vif, vpr, and env/vpu 2 RNAs. This could potentially result in the appearance of further spliced RNAs in the cytoplasm due to removal of introns containing sequences that would normally prevent transport of these RNAs from the nucleus (CRS). The design of the positions of oligonucleotide primer pairs was such that further RNA splicing of vif, vpr, and env/vpu 2 RNAs at known intron positions would not be detected (Arrigo et al. 1990). However, to determine whether the singly spliced RNAs produced by the mutants had suffered any major alterations in sizes by removal of additional uncharacterized introns, purified cytoplasmic RNAs from transfections with mutant and wild-type constructs were analyzed by fractionation by size on sucrose gradients. Fractions were collected, and the RNA recovered from each fraction was subjected to RNA PCR analysis. An aliquot of each fraction was analyzed on an agarose gel to determine the location within the gradient of $28 \mathrm{~S}$ and $18 \mathrm{~S}$ rRNAs. The results are shown in Figure 5. nef RNA, which is $\sim 1.8 \mathrm{~kb}$ in size, showed its major peak near $18 \mathrm{~S}$ rRNA with both mutant and wild-type constructs. vif, vpr, and env/vpu 2 RNAs, which should have sizes of $\sim 5.3,4.8$, and $4.2 \mathrm{~kb}$, respectively, with both the wild-type and $r e v^{-}$mutant, showed major peaks within the appropriate fractions of the gra- 


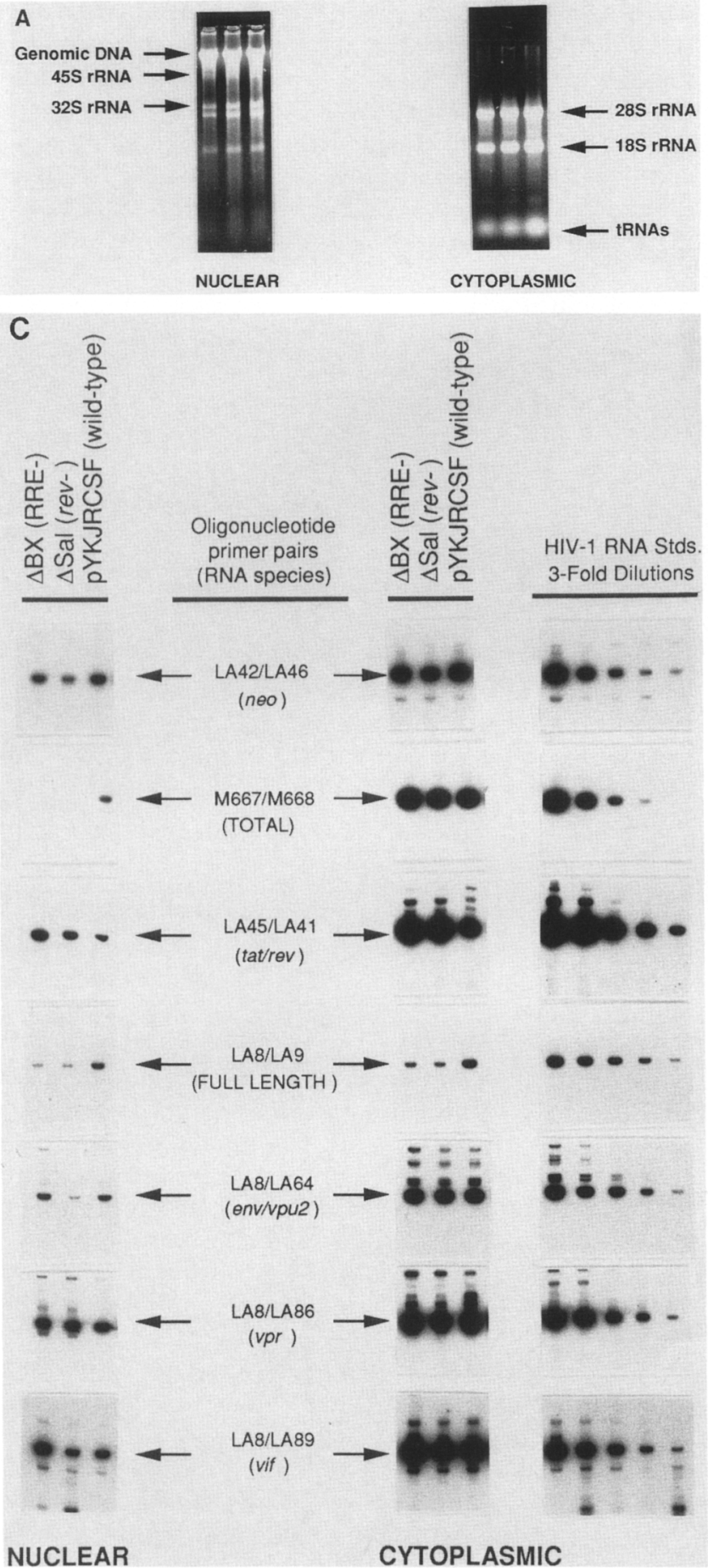

NUCLEAR
CYTOPLASMIC

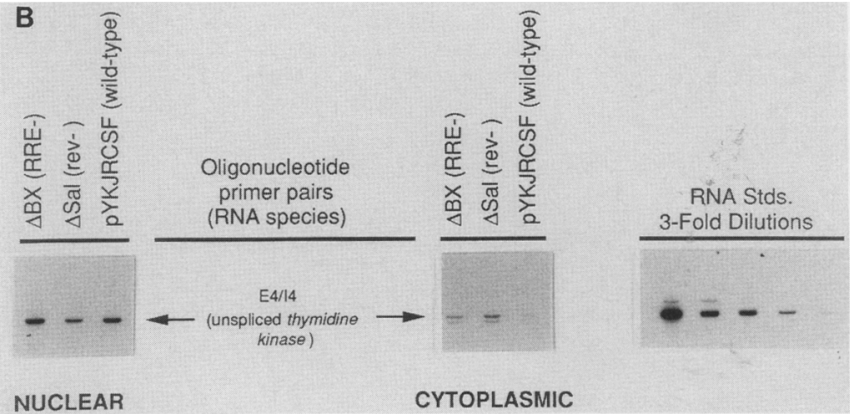

Figure 3. Analysis of the effect of Rev on nuclear and cytoplasmic levels of HIV-1 RNAs in lymphoid cells. (A) Agarose gel analysis of cell fractionations. Nuclear and cytoplasmic RNA was prepared from $10^{7} 729$ cells electroporated for $48 \mathrm{hr}$ previously. Five percent of the recovered fractions were each run on a $1 \%$ agarose gel and stained with ethidium bromide. $(B)$ Results of RNA PCR analysis using oligonucleotides specific for unspliced thymidine kinase pre-mRNA. Nuclear and cytoplasmic RNA was prepared from $10^{7} 729$ cells electroporated with $45 \mu \mathrm{g}$ of the indicated proviral construct and $5 \mu \mathrm{g}$ of CMV-neo. RNA PCR was performed on $10^{5}$ cell equivalents of nuclear or cytoplasmic RNA, as described (Fig. 2). RNA standards were diluted sequentially threefold from a nuclear RNA sample. (C) Results of RNA PCR analysis using the designated oligonucleotide primer pairs to detect specific RNAs in electroporated lymphoid cells. The same nuclear and cytoplasmic RNAs as in $B$ were used. RNA PCR analysis was performed on $4 \times 10^{5}$ cell equivalents of nuclear or cytoplasmic RNA, as described (Fig. 2). RNA standards were diluted sequentially threefold from HIV-1-transfected or -infected cell RNA samples.

splicing in the mutants that might remove introns within the vif, vpr, or env/vpu 2 RNAs should be readily detectable unless the removed intron is quite small. These results indicate that the vif, vpr, and env/vpu 2 RNAs observed in the cytoplasm of cells electroporated with mutant constructs are not further spliced and that these RNAs are identical to wild-type vif, vpr, and env/ vpu 2 RNAs. 


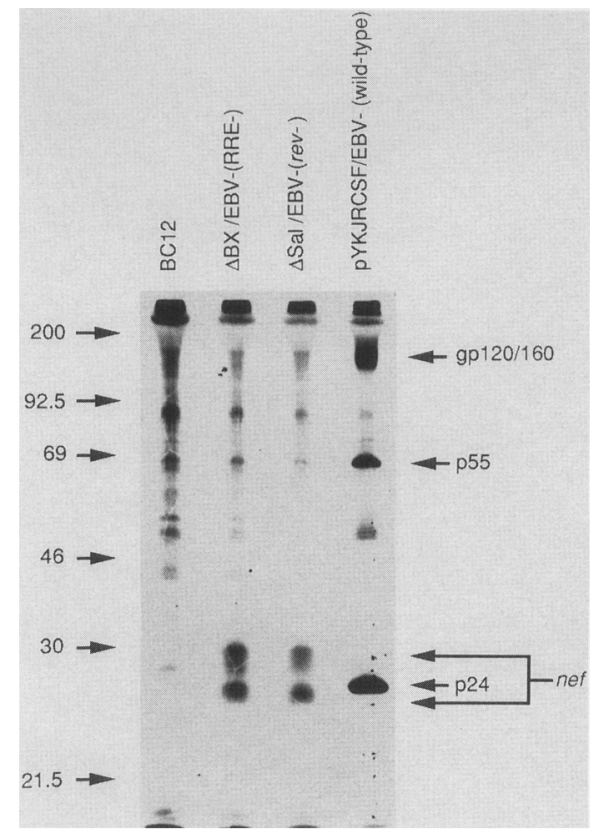

Figure 4. Immunoprecipitation of HIV-1-specific proteins from wild-type and mutant electroporations. Results of radioimmunoprecipitation assays performed on $5 \times 10^{6} 729$ cells electroporated with $25 \mu \mathrm{g}$ of the indicated constructs. Cells were labeled with $\left[{ }^{35} \mathrm{~S} \mid\right.$ methionine and $\left[{ }^{35} \mathrm{~S}\right]$ cysteine for $24 \mathrm{hr}$ at $48 \mathrm{hr}$ postelectroporation. One-fifth of each lysate was immunoprecipitated with pooled human $\alpha$-HIV-1 serum. The positions of gag, env, and nef gene products are indicated. The positions of molecular mass markers (in kilodaltons) are shown. The plasmid BC12 (Cullen 1986) was used as a negative control for HIV-1 protein production.

Rev is necessary for the assembly of polysomes onto vif, vpr, and env/vpu 2 RNAs

With both $\mathrm{RRE}^{-}$and $\mathrm{rev}^{-}$mutants, we had shown that levels of singly spliced RNAs equivalent to wild-type levels were present in the cytoplasm of lymphoid cells, and no structural proteins were detected. It appeared that Rev might be necessary to allow the translation of the cytoplasmic singly spliced RNAs. Therefore, we wished to determine the molecular nature of the cytoplasmic singly spliced RNAs with the mutants. Association of mRNAs with polysomes is generally thought to reflect the translational activity of these mRNAs (for review, see Lewin 1980). Therefore, we determined the extent of polysomal association of the cytoplasmic vif, vpr, and env/vpu 2 RNAs found with both the rev ${ }^{-}$and $\mathrm{RRE}^{-}$ mutants. Electroporated cells were treated with cycloheximide to "freeze" ribosome progression on mRNA and were separated into nuclear and cytoplasmic fractions. The cytoplasmic fraction was applied directly to a sucrose gradient, and the RNAs were fractionated by velocity sedimentation on the basis of the extent of their assembly into high-molecular-weight fractions, reflecting polysome assembly. RNA was prepared from each of these fractions. An aliquot of RNA from each fraction was run on an agarose gel to determine the location within each gradient of $18 \mathrm{~S}$ rRNA, which is indicative of the $40 \mathrm{~S}$ ribosomal subunit, and $28 \mathrm{~S}$ rRNA, indicative of the $60 \mathrm{~S}$ ribosomal subunit, as well as the first fraction that might contain the $80 \mathrm{~S}$ monosome complex (data not shown). All fractions smaller than the $80 \mathrm{~S}$ complex were considered nonpolysomal, whereas all fractions larger than the 80S complex were considered polysomal. RNA PCR analysis was performed on RNA recovered from each gradient fraction by using oligonucleotide primer pairs specific for HIV-1 RNAs and $\beta$-actin RNA as a control for an actively translated cellular RNA. The results are shown in Figure 6. A comparison of the polysome profiles obtained with the $\mathrm{rev}^{-}$mutant and wild type is shown in Figure 6A. RNA standards were included to allow direct quantitation of RNA in mutant and wildtype profiles. tat/rev RNA shows a similar profile with the $\mathrm{rev}^{-}$mutant and wild type, with RNA distributed among both nonpolysomal and polysomal RNAs. Consistent with our studies described above, the wild-type profile demonstrates a decrease in signal intensities greater than ninefold across the gradient (exposures are adjusted to visualize the distribution more easily). In contrast, env/vpu 2 RNA shows a dramatic difference in distribution between the wild type and mutant. Wild type exhibits an env/vpu 2 profile similar to that of tat/ rev, demonstrating predominantly polysomal association. However, the $\mathrm{reV}^{-}$mutant exhibits a lack of this polysomal association, instead exhibiting an association with a complex $\sim 40 \mathrm{~S}-80 \mathrm{~S}$ in size. Approximately $90 \%$ of the cytoplasmic env/vpu 2 RNA with the mutant fractionated at a size of $80 S$ or less, whereas $>75 \%$ of the cytoplasmic env/vpu 2 RNA with the wild-type fractionated at a size of $>80$ S.

We also compared the polysome profiles of wild type and the $\mathrm{RRE}^{-}$mutant in a second experiment (Fig. 6B), in which we examined more closely additional HIV-1 RNA species, as well as a highly expressed cellular gene, spliced $\beta$-actin. Primers specific for $\beta$-actin RNA showed a peak of nonpolysomal RNA and a peak of polysomal RNA extending to the bottom of the gradient with both wild-type and the $\mathrm{RRE}^{-}$mutant. A similar profile of polysomal RNA was seen with both tat/rev- and nefspecific primers with both mutant and wild type, indicating productive assembly of ribosomes onto these RNAs. However, a dramatic difference was seen between wild type and mutant in the polysome profiles of the singly spliced vif, vpr, and env/vpu 2 RNAs. With the wild type, each of the three singly spliced RNA species associated with polysomes in a nearly identical pattern to that of tat/rev RNA. In contrast, the $\mathrm{RRE}^{-}$mutant demonstrated a nearly complete lack of any polysomal association of vif, vpr, or env/vpu 2 RNAs, although the profile of tat/rev RNA with the mutant was similar to that of wild type. Polysome profiles similar to that of the $\mathrm{RRE}^{-}$mutant were seen with the rev ${ }^{-}$mutant in this experiment (data not shown).

The singly spliced HIV-1 RNAs of the mutant were found predominantly in a few peak fractions corresponding to a size between $40 \mathrm{~S}$ and $80 \mathrm{~S}$. Therefore, with the mutant, RNAs appear to be assembled into a ribonucle- 


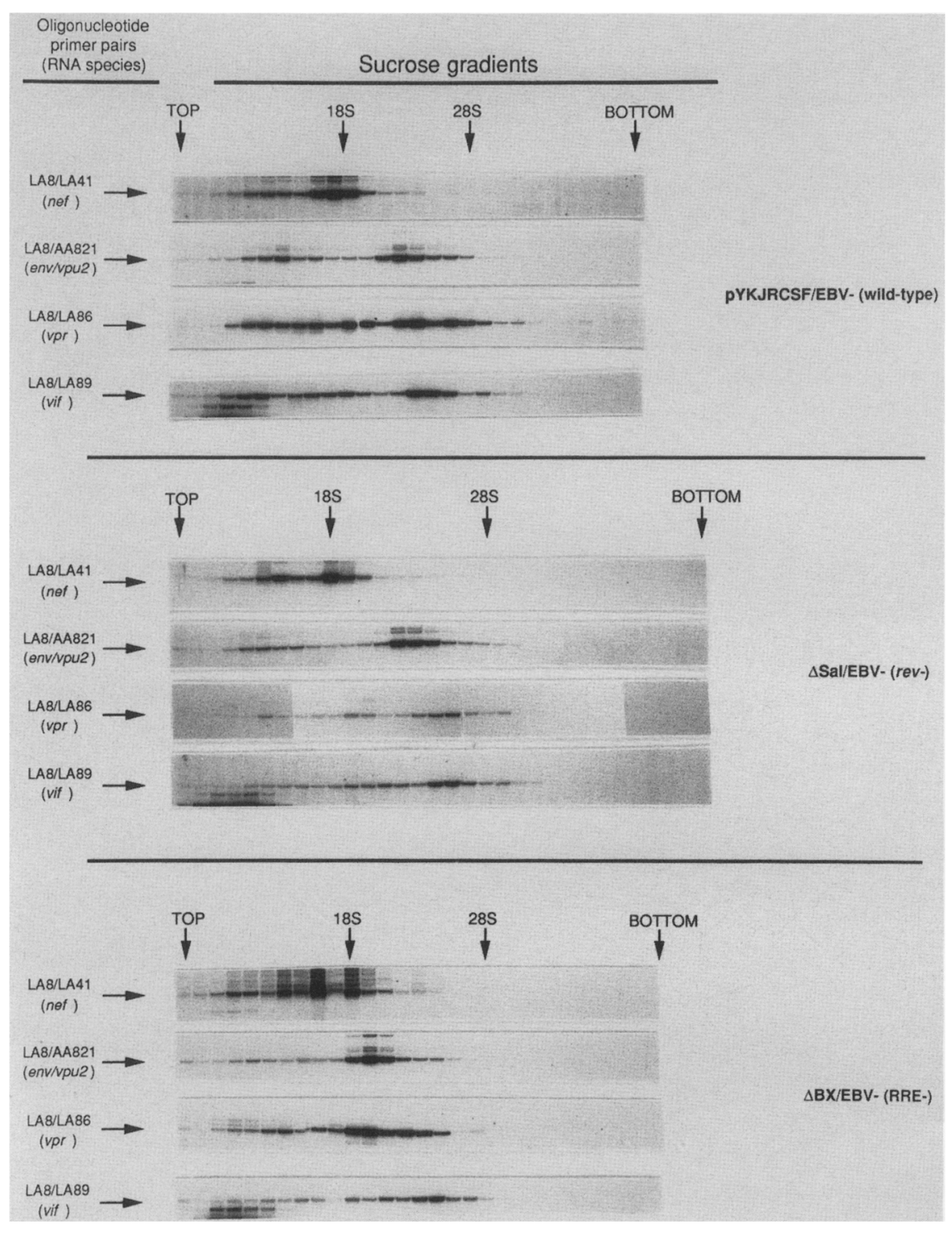

Figure 5. Sucrose gradient determination of the effect of Rev on the sizes of HIV-1 RNAs. Results of sucrose gradient separations performed on $10^{7}$ cell equivalents of purified cytoplasmic RNAs from $10^{8} 729$ cells electroporated with $500 \mu \mathrm{g}$ of the indicated constructs. Fractions were collected, and RNA was prepared. The locations of $28 \mathrm{~S}$ and 18S RNAs are indicated. RNA PCR analysis was performed as in Fig. 2, using the indicated oligonucleotide primer pairs specific for each HIV-1 RNA. One-twelfth of the RNA recovered from each fraction was used in each RNA PCR analysis. The position of the top and bottom of each gradient is shown. oprotein complex that may not allow association of these RNAs onto polysomes.

These results indicate that although vif, vpr, and env/ vpu 2 RNAs accumulate in the cytoplasm of cells in the absence of Rev or the RRE, those RNAs are not efficiently assembled onto polysomes. Therefore, Rev appears to be necessary for production of Env and, presumably, Vif, Vpr, and Vpu proteins, not by facilitating the transport of these RNAs into the cytoplasm but, rather, by allowing the assembly of polysomes onto these RNAs.

\section{Discussion}

Rev can modulate unspliced and singly spliced HIV-1 RNA levels

We used transient expression from proviral constructs to examine the effect of Rev on HIV-1 protein and RNA expression. An infectious molecular clone of a primary isolate, HIV-1 $1_{\mathrm{IR}-\mathrm{CSF}}$, was employed. These experiments were conducted using a lymphoid cell line, 729 , in comparison to the more routinely used COS fibroblast cell line. In this way, we hoped to mimic more closely in vivo regulation of HIV-1 by Rev and to detect any cell type-specific regulation by HIV-1 Rev. In agreement with previous reports, Rev and the RRE are necessary for expression of HIV-1 in both COS and 729 cells. This appears to be a direct result of the lack of production of HIV-1 structural proteins in the mutant provirus. As found previously, Rev was necessary for high-level cytoplasmic accumulation of both full-length and env/vpu 2 RNAs in the COS system. In this system, reduced cytoplasmic HIV-1 RNAs encoding the structural proteins could at least partly explain the lack of HIV-1 structural production in the absence of Rev. Unexpectedly, in 729 cells, Rev did not appear to affect the cytoplasmic levels 


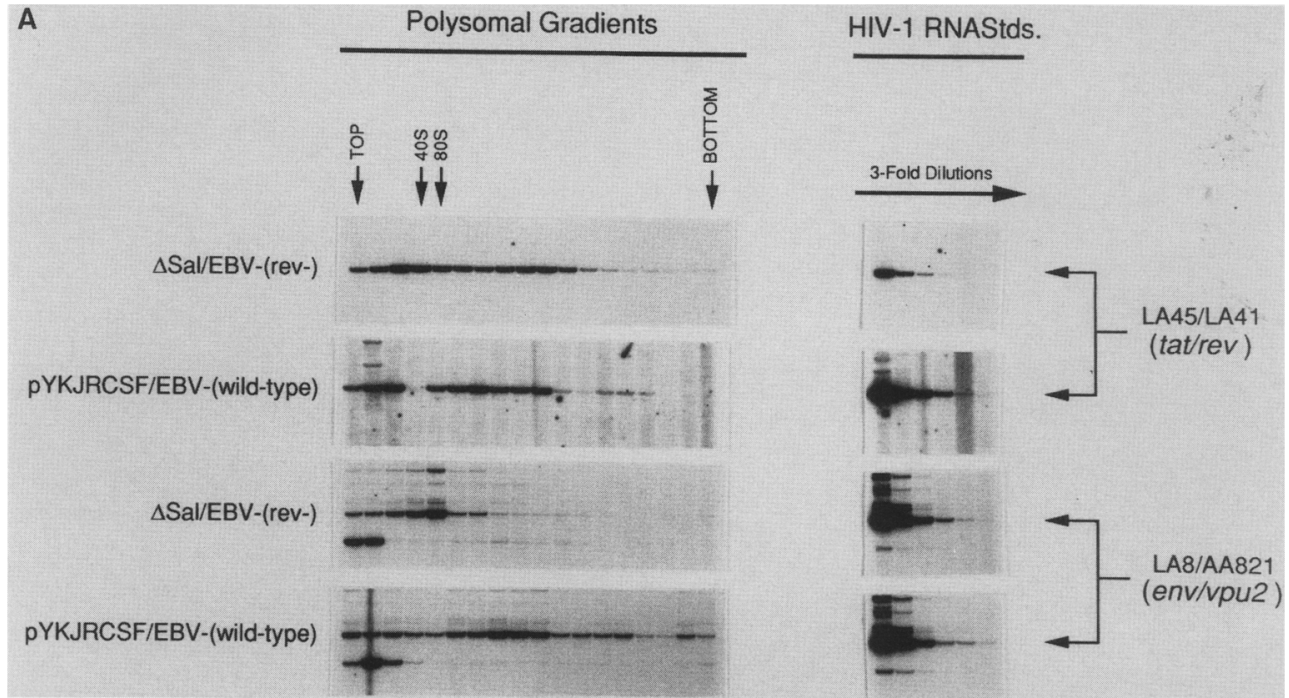

Figure 6. The effect of Rev on the polysomal profile of HIV-1 RNAs. (A) Results of polysomal fractionations of cytoplasmic RNAs from electroporated cells on sucrose gradients. 729 cells $\left(10^{8}\right)$ were electroporated with $500 \mu \mathrm{g}$ of the indicated mutant or wildtype constructs. The cytoplasmic fraction from $5 \times 10^{7}$ of these cells was applied to a sucrose gradient. Fractions were collected, and RNA was prepared. Equivalent amounts of each fraction were subjected to RNA PCR analysis with each of the oligonucleotide pairs shown. RNA PCR analysis was as in Fig. 2 . The locations of the $40 \mathrm{~S}$ ribosomal subunit and the 80 S monosomal complex are indicated. HIV-1 RNA standards were diluted sequentially threefold from an HIV-1-transfected cell RNA sample. Identical standards were used for mutant and wild-type RNA PCR analysis to allow direct comparison. (B) Same as above, but 20 cycles of amplification were used for analysis of $\beta$-actin.

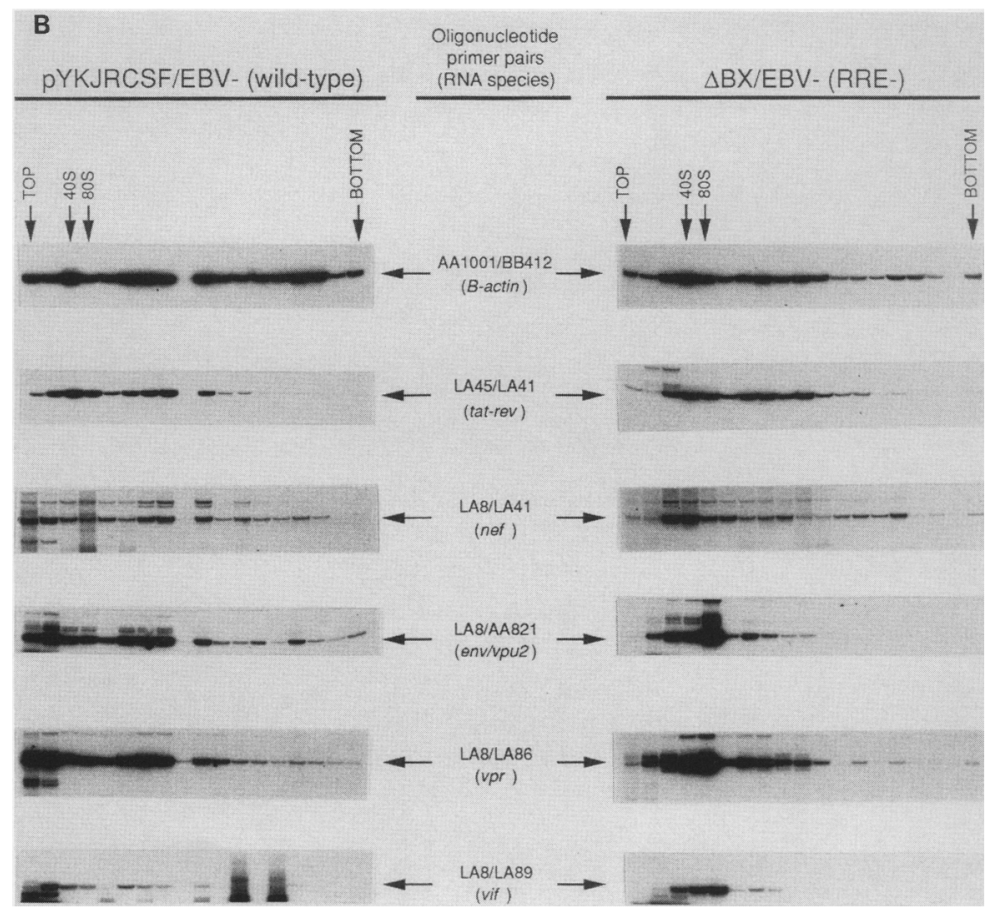

of the singly spliced vif, vpr, or env/vpu 2 RNAs relative to wild type. Thus, in lymphoid cells, an additional Revdependent function is necessary for expression of HIV-1 structural proteins from the singly spliced HIV-1 RNAs. In addition, preliminary results using other lymphoid cell lines indicate that the results with 729 cells are similar to those seen with other B- and T-cell lines (data not shown). We are currently attempting to perform experiments in PBL to determine whether this effect is evident.

\section{Rev is capable of modulating HIV-1 mRNA translation}

Examination of the polysomal association of the cytoplasmic HIV-1 RNAs in 729 cells demonstrated that in contrast to RNAs not regulated by Rev, the vif, vpr, and env/vpu 2 RNAs were unable to assemble into polysomal RNA in the absence of Rev. This observation explains the failure of cytoplasmic singly spliced RNAs to be translated in the absence of Rev. Rev did affect the levels of full-length HIV-1 RNA in the cytoplasm, but the cytoplasmic RNA levels were not concordant with Gag p24 expression. Polysomal analysis of the cytoplasmic full-length HIV-1 RNA, present at 10- to 20-fold reduced but readily detectable levels in the mutants, was also not associated with polysomes (data not shown). This provides an explanation for the nearly total lack of Gag p24 expression with the mutants.

The block to assembly of polysomes onto cytoplasmic RNA might be at several levels. It is possible that the 
nonpolysomal RNA is compartmentalized so that it is inaccessible to the translational machinery. Some structure of the RNA may make it unable to associate with polysomes, or it is possible that a negative factor(s) is bound to the RNA that interferes with the initiation or elongation steps of translation. It is therefore noteworthy that the cytoplasmic RNA in the mutants is not free and appears to be associated with a $40 \mathrm{~S}-80 \mathrm{~S}$ complex. Preliminary experiments have shown that this complex is sensitive to treatment with EDTA (data not shown). It is not presently clear whether this complex is involved in any normal cellular pathway. One possibility for the identity of this complex is discussed below.

\section{Bimodal effect of Rev}

Other systems have been used to address the role of Rev in regulation of HIV-1 RNA expression. A clear link has been established in all systems between the presence of Rev and expression of HIV-1 structural proteins. However, it is clear that the effect of Rev on cytoplasmic accumulation of singly spliced HIV-1 RNAs does not always appear to correlate with protein expression. Therefore, although Rev is capable of exerting some effect on the cytoplasmic accumulation of HIV-1 RNAs, particularly evident in COS cells, Rev also has the ability to allow translation of cytoplasmic RNAs containing the RRE. Whether this additional capability is effective in the COS system is difficult to determine. It is possible that Rev functions at the levels of both splicing/transport and translation in both COS and lymphoid cell types. However, the effect of Rev on translation in COS cells may be masked by the decreased levels of cytoplasmic Rev-responsive RNAs in the absence of Rev. This may be due to different rates of splicing, stability, and transport in COS and lymphoid cells.

We propose one possible model that may explain both the block to polysome assembly and the effect of Rev on cytoplasmic RNA accumulation. As yet, poorly defined regions of the RNA, termed the CRS, appear to be required to retain RNA in the nucleus in the COS system; thus, such elements may be a candidate to be bound by components of the 40S-80S complex seen with the mutant RNAs. This binding may occur first in the nucleus, and this complex might increase the rate of spliceosome assembly. Results demonstrating the importance of splice site recognition suggested that regulation by Rev may involve dissociation of splicing components and pre-mRNA (Chang and Sharp 1989). Both unspliced and singly spliced HIV-1 RNAs might then be transported to the cytoplasm, where those bound by the CRS/40S-80S complex would be prevented from associating with polysomes in the absence of Rev. In the presence of Rev, the RNAs would not be bound by the complex and would be free to associate with polysomes. Removal of CRS elements by splicing to tat/rev RNAs would have the same effect. Under our experimental conditions in COS cells, transport of RNAs bound by this complex might be inefficient. Alternatively, the rate of splicing might exceed the rate of transport, or this complex may result in de- creased cytoplasmic stability of associated HIV-1 RNAs. Further research is necessary to determine the validity of this model and to determine how Rev is able to alleviate the block to expression of the various unspliced and singly spliced HIV-1 RNAs. In particular, further characterization of the cytoplasmic nonpolysome complex, as well as determination as to whether this complex is present in the nucleus, may provide insight into a unifying mechanism of action.

\section{Materials and methods}

Tissue culture and electroporation

The 729 B-cell and COS-cell lines were maintained in Iscove's medium supplemented with $5 \%$ fetal calf serum (FCS). Before electroporation, cells were suspended at a concentration of $2 \times 10^{7}$ cells $/ \mathrm{ml}$ in RPMI 1640 medium supplemented with $20 \%$ FCS. Cells $\left(10^{7}\right)$ were electroporated with a total of $50 \mu \mathrm{g}$ of plasmid DNA, as described (Cann et al. 1988). For sucrose gradient fractionation, 10 electroporations of $10^{7}$ cells $\left(10^{8}\right.$ cells total) were performed and pooled in $100 \mathrm{ml}$ of Iscove's medium supplemented with $10 \%$ FCS. Cells and viral supernatants were harvested $48 \mathrm{hr}$ postelectroporation. Gag p24 production was measured by ELISA (Abbott Laboratories).

\section{Proviral constructs}

$\triangle \mathrm{BX}, \triangle \mathrm{Sal}$, and pYRJRCSF have been described previously (Arrigo et al. 1989). To increase the expression of HIV-1-specific RNA and protein, the Epstein-Barr vinus (EBV) origin of replication (OriP) was cloned into both mutant and wild-type constructs at a unique EcoRI site downstream of the $3^{\prime}$ long terminal repeat (LTR). The plasmid constructions with a sense orientation of OriP in relation to the HIV-l genome were denoted $/ \mathrm{EBV}^{+}$, whereas constructs with the antisense orientation of OriP were denoted $/ \mathrm{EBV}^{-}$. Insertion of this origin allowed for augmented levels of viral RNAs to be obtained from these constructs in the 729 cell line (which is transformed by EBV) relative to constructs lacking these sequences (Table 1, experiment 1). Insertion of OriP did not alter the pattern of cytoplasmic expression of vif, $v p r$, and env/vpu 2 RNAs of mutant and wild type (data not shown).

\section{RNA preparation and RNA PCR analysis}

Nuclear and cytoplasmic fractions and RNA extraction were performed as described previously (Arrigo et al. 1989). Briefly, cell pellets were lysed in $0.65 \% \mathrm{NP}-40,150 \mathrm{~mm} \mathrm{NaCl}, 10 \mathrm{~mm}$ Tris ( $\mathrm{pH} 7.8$ ), and $1.5 \mathrm{mM} \mathrm{MgCl}_{2}$. Nuclei were pelleted by lowspeed centrifugation. The nuclear pellet was washed with the same lysis buffer, and the cytoplasmic fraction was subjected to an additional high-speed centrifugation to remove any contaminating nuclei.

RNA PCR analysis was performed essentially as described (Arrigo et al. 1989). Minor modifications to this procedure were made. Moloney murine leukemia virus reverse transcriptase was substituted for avian myeloblastosis virus reverse transcriptase in the primer extension reaction. PCR amplification was performed for 25 cycles of denaturation at $94^{\circ} \mathrm{C}$ for $1 \mathrm{~min}$ and polymerization at $65^{\circ} \mathrm{C}$ for $2 \mathrm{~min}$. Alterations in the number of cycles of amplification used during the RNA PCR anal$y$ sis of $\beta$-actin RNA are noted in the text. The nucleotide sequences of the oligonucleotide primers used for PCR are described (Arrigo et al. 1989, 1990) and are as follows: AA821, 
5'-GCTAATATTTGTAAAGGTTGCATTACATGCACTAC-3' ; AA1001, 5'-CACAGAGCCTCGCCTTTGCC-3'; BB412, 5'-CACATGCCGGAGCCGTTGTC-3'; LA42, 5' -ACGCTGCCGCAAGCACTCAG-3'; LA46, 5'-TGTCCAGATAGCCCAGTAGC-3'; E4, 5'-AGACGTGGCCCAGGAGGCCC-3'; I4, 5'-CAGATAACTTCCAAGTCAGC-3'. The AA821 oligonucleotide primer is a 35-nucleotide analog of the previously described LA64 oligonucleotide primer (Arrigo et al. 1990). The AA1001 and BB412 oligonucleotide primers are homologous to nucleotides $31-50$ and $1142-1123$ of the human $\beta$-actin cDNA clone, respectively (Nakajima-Iijima et al. 1985). Numbering is in reference to the cap site, and the BB412 oligonucleotide primer was in antisense orientation to the mRNA sequence; it was therefore used in the primer extension reaction. This oligonucleotide primer pair flanks the first intron of human $\beta$-actin and should specify production of a 106-bp spliced $\beta$-actin-specific product by RNA PCR analysis. The LA42/LA46 oligonucleotide primers are homologous to sequences of the neomycin resistance gene found within the pSVneo construct. LA42 and LA46 oligonucleotide primers are homologous to nucleotides 2-21 and 119100 , respectively. Numbering is in the direction of neo transcription and begins at the HindIII site. This oligonucleotide primer pair should specify the production of a 118-bp neo-specific product by RNA PCR analysis. Oligonucleotide primers E4 and $I 4$ are homologous to nucleotides $4431-4450$ (exon 4 ) and nucleotides $4570-4551$ (intron 4) of the human thymidine kinase pre-mRNA. This oligonucleotide primer pair directs the synthesis of a 121-bp product specific for unspliced thymidine kinase pre-mRNA by RNA PCR analysis.

\section{Immunoprecipitations}

729 B cells $\left(5 \times 10^{6}\right)$ were electroporated with $25 \mu \mathrm{g}$ of proviral DNA. At $48 \mathrm{hr}$ postelectroporation, the cells were pelleted and resuspended in $4 \mathrm{ml}$ of cysteine-free, methionine-free RPMI 1640 medium supplemented with $20 \%$ FCS. Trans ${ }^{35}$ S label 1400 $\mu \mathrm{Ci}$ ) (ICN Biochemicals) was added, and the cells were allowed to incorporate label for $24 \mathrm{hr}$. The cells were pelleted and washed twice with cold phosphate-buffered saline and were lysed in $5 \mathrm{ml}$ of RIPA lysis buffer $(0.05 \mathrm{M}$ Tris at $\mathrm{pH} 8.0,0.1 \%$ sodium lauryl sulfate, $1.0 \%$ Triton X-100, $2.0 \mathrm{~mm}$ phenylmethylsulfonyl fluoride, $0.15 \mathrm{M} \mathrm{NaCl}$, and $1.0 \%$ deoxycholate) for 15 min. The lysate was centrifuged at $36,000 \mathrm{rpm}$ for $1 \mathrm{hr}$ in an SW55 rotor (Beckman). One milliliter of lysate was added to 10 $\mu \mathrm{l}$ of pooled patient serum (Abbott Laboratories) that had been preincubated with $300 \mu$ l of unlabeled 729 cell lysate for 30 min. After $1 \mathrm{hr}$ of incubation, $100 \mu \mathrm{l}$ of $10 \%$ protein A-Sepharose CL-4B (Pharmacia) was added, and the incubation continued for $1 \mathrm{hr}$. Proteins were separated on a $10 \%$ polyacrylamide gel with $3.5 \%$ stacking gel. The gel was treated with Enhance (DuPont/NEN) and visualized by fluorography.

\section{Sucrose gradient centrifugation}

Fractionation of purified cytoplasmic RNAs was performed by layering purified cytoplasmic RNA from $2.5 \times 10^{7}$ electroporated cells onto a $15-30 \%$ linear sucrose gradient $(0.01 \mathrm{M}$ Tris at $\mathrm{pH} 7.4,0.005 \mathrm{M}$ EDTA, and $0.5 \%$ sodium lauryl sulfate), essentially as described (Krzyzek et al. 1978). Gradients were centrifuged at $25,000 \mathrm{rpm}$ for $16.5 \mathrm{hr}$ at $20^{\circ} \mathrm{C}$ in an SW4l rotor (Beckman). Fractions $(0.4 \mathrm{ml})$ were collected and precipitated with ethanol, and $16 \mu \mathrm{g}$ of yeast tRNA was added to each fraction as carrier. Pellets were resuspended in water and phenol/chloroform $(1: 1)$, extracted and ethanol-precipitated, and resuspended in water. Aliquots were analyzed by electrophoresis on a $1.0 \%$ agarose gel to determine the location within the gradient of $28 \mathrm{~S}$ and $18 \mathrm{~S}$ rRNAs.

\section{Polysomal RNA analysis}

Fractionation of polysomal RNAs was performed as follows. Electroporated cells $\left(10^{8}\right)$ were harvested at $48 \mathrm{hr}$ postelectroporation by addition of cycloheximide to $1 \mu \mathrm{g} / \mathrm{ml}$ in the culture media. Cells were pelleted and washed once with phosphatebuffered saline containing $1 \mu \mathrm{g} / \mathrm{ml}$ cycloheximide. Cells were lysed in NP-40 lysis buffer $(0.65 \% \mathrm{NP}-40,150 \mathrm{mM} \mathrm{NaCl}, 10 \mathrm{~mm}$ Tris at $\mathrm{pH} 7.8$, and $1.5 \mathrm{mM} \mathrm{MgCl}_{2}$ ) with $1 \mu \mathrm{g} / \mathrm{ml}$ of cycloheximide. After the addition of 200 units of RNasin (Promega), nuclei were removed by two centrifugations at 13,000 rpm for 5 min. An aliquot was taken for preparation of purified cytoplasmic RNA. The cytoplasmic fraction $(500 \mu l)$ from $5 \times 10^{7}$ electroporated cells was layered onto a $15-40 \%$ linear sucrose gradient (10 mM Tris at $\mathrm{pH} 8.6,5 \mathrm{~mm} \mathrm{MgCl}_{2}$, and $100 \mathrm{~mm} \mathrm{NaCl}$ ) and centrifuged in an SW41 rotor at $32,500 \mathrm{rpm}$ for $2 \mathrm{hr}$, as described (Gay et al. 1989). Fractions $(600 \mu 1)$ were taken, and 16 $\mu \mathrm{g}$ of yeast tRNA was added as carrier. RNA was purified as described (Arrigo et al. 1989). These RNAs were subjected to an additional phenol/chloroform $(1: 1)$ extraction and ethanol precipitation. Pellets were resuspended in water, and aliquots were analyzed by electrophoresis on a $1.0 \%$ agarose gel to determine the location of polysomal and nonpolysomal fractions.

\section{Acknowledgments}

We thank Stacy Weitsman, Alan Go, Tsuneko Akashi, Dale Sison, and Amadou Diagne for technical assistance; David Ho for providing pooled $\alpha$-HIV-1 patient senum; Jerome Zack, Patrick Green, David Camerini, William O’Brien, Shen Pang, Michele Yip, Gerold Feuer, Kelly Arrigo, and Tarsem Moudgil for helpful discussions; and Wendy Aft for preparation of the manuscript. This work was supported by the National Institutes of Health (grants CA 38597, AI 27221, and AI 29107). S.J.A. is a Fellow of the Leukemia Society of America, and I.S.Y.C. is a Scholar of the Leukemia Society of America.

The publication costs of this article were defrayed in part by payment of page charges. This article must therefore be hereby marked "advertisement" in accordance with 18 USC section 1734 solely to indicate this fact.

\section{References}

Ahmad, N., R.K. Maitra, and S. Venkatesan. 1989. Rev-induced modulation of Nef protein underlies temporal regulation of human immunodeficiency virus replication. Proc. Natl. Acad. Sci. 86: 6111-6115.

Arrigo, S.J., S. Weitsman, J.D. Rosenblatt, and I.S.Y. Chen. 1989. Analysis of rev gene function on human immunodeficiency virus type 1 replication in lymphoid cells by using a quantitative polymerase chain reaction method. I. Virol. 63: 4875-4881.

Arrigo, S.J., S. Weitsman, J.A. Zack, and I.S.Y. Chen. 1990. Characterization and expression of novel singly spliced RNA species of human immunodeficiency virus type 1. I. Virol. 64: 4585-4588.

Arya, S.K., G. Chan, S.J. Josephs, and F. Wong-Staal. 1985. Transactivator gene of human T-lymphotropic virus type III. Science 229: 69-73.

Cann, A.J., Y. Koyanagi, and I.S.Y. Chen. 1988. High efficiency transfection of primary human lymphocytes and studies of gene expression. Oncogene 3: 123-128. 
Chang, D.D. and P.A. Sharp. 1989. Regulation by HIV Rev depends upon recognition of splice sites. Cell 59: 789-795.

Cullen, B.R. 1986. Trans-activation of human immunodeficiency virus occurs via a bimodal mechanism. Cell 46: 973-982.

Dayton, A.I., J.G. Sodroski, C.A. Rosen, W.C. Goh, and W.A. Haseltine. 1986. The trans-activator gene of human T-cell lymphotropic virus type III is required for replication. Cell 44: $941-947$.

Emerman, M., R. Vazeux, and K. Peden. 1989. The rev gene product of the human immunodeficiency virus affects envelope-specific RNA localization. Cell 57: 1155-1165.

Feinberg, M.B., R.F. Jarrett, A. Aldovini, R.C. Gallo, and F. Wong-Staal. 1986. HTLV-III expression and production involve complex regulation at the levels of splicing and translation of viral RNA. Cell 46: 807-817.

Felber, B.K., M. Cladaras-Hadzopoulou, C. Cladaras, T. Copeland, and G.N. Pavlakis. 1989. Rev protein of human immunodeficiency virus type 1 affects the stability and transport of the viral mRNA. Proc. Natl. Acad. Sci. 86: 1495-1499.

Gallo, R., F. Wong-Staal, L. Montagnier, W.A. Haseltine, and M. Yoshida. 1988. HIV/HTLV gene nomenclature. Nature 333: 504-505.

Gay, D.A., S.S. Sisodia, and D.W. Cleveland. 1989. Autoregulatory control of $\beta$-tubulin mRNA stability is linked to translation elongation. Proc. Natl. Acad. Sci. 86: 5763-5767.

Gudas, J.M., G.B. Knight, and A.B. Pardee. 1988. Nuclear posttranscriptional processing of thymidine kinase mRNA at the onset of DNA synthesis. Proc. Natl. Acad. Sci. 85: 47054709.

Hadzopoulou-Cladaras, M., B.K. Felber, C. Cladaras, A. Athanassopoulos, A. Tse, and G.N. Pavlakis. 1989. The rev (trs) art) protein of human immunodeficiency virus type 1 affects viral mRNA and protein expression via a cis-acting sequence in the env region. $J$. Virol. 63: 1265-1274.

Hammarskjold, M.-L., J. Heimer, B. Hammarskjold, I. Sangwan, L. Albert, and D. Rekosh. 1989. Regulation of human immunodeficiency virus env expression by the rev gene product. $J$. Virol. 63: 1959-1966.

Knight, D.M., F.A. Flomerfelt, and J. Ghrayeb. 1987. Expression of the art/trs protein of HIV and study of its role in viral envelope synthesis. Science 236: 837-840.

Krzyzek, R.A., M.S. Collett, A.F. Lau, M.L. Perdue, J.P. Leis, and A.J. Faras. 1978. Evidence for splicing of avian sarcoma virus 5 '-terminal genomic sequences onto viral-specific RNA in infected cells. Proc. Natl. Acad. Sci. 75: 1284-1288.

Le, S.V., J.H. Chen, M.J. Braun, M.A. Gonda, and J.V. Maizel. 1988. Stability of RNA stem-loop structure and distribution of nonrandom structure in the human immunodeficiency virus (HIV-1). Nucleic Acids Res. 16: 5153-5168.

Lewin, B. 1980. Gene expression 2, 2nd ed. John Wiley \& Sons, New York.

Malim, M.H., J. Hauber, R. Fenrick, and B.R. Cullen. 1988. Immunodeficiency virus rev trans-activator modulates the expression of the viral regulatory genes. Nature 335: 181-183.

Malim, M.H., S. Bohnlein, J. Hauber, and B.R. Cullen. 1989a. Functional dissection of the HIV-1 Rev transactivator-Derivation of a trans-dominant repressor of Rev function. Cell 58: 205-214.

Malim, M.H., J. Hauber, S.-Y. Le, J.V. Maizel, and B.R. Cullen. $1989 \mathrm{~b}$. The HIV-1 rev trans-activator acts through a structured target sequence to activate nuclear export of unspliced viral mRNA. Nature 338: 254-257.

Malim, M.H., L.S. Tiley, D.F. McCarn, J.R. Rusche, J. Hauber, and B.R. Cullen. 1990. HIV-1 structural gene expression requires binding of the Rev trans-activator to its RNA target sequence. Cell 60: 675-683.
Muesing, M.A., D.H. Smith, C.D. Cabradilla, C.V. Benton, L.A. Lasky, and D.J. Capon. 1985. Nucleic acid structure and expression of the human AIDS/lymphadenopathy retrovirus. Nature 313: 450-458.

Muesing, M.A., D.H. Smith, and D. Capon. 1987. Regulation of mRNA accumulation by human immunodeficiency virus trans-activator protein. Cell 48: 691-701.

Nakajima-Iijima, S., H. Hamada, P. Reddy, and T. Kakunaga. 1985. Molecular structure of the human cytoplasmic betaactin gene: Interspecies homology of sequences in the introns. Proc. Natl. Acad. Sci. 82: 6133-6137.

Peterlin, M., P. Luciw, P. Barr, and M. Walker. 1986. Elevated levels of mRNA can account for the trans-activation of human immunodeficiency virus. Proc. Natl. Acad. Sci. 83: $9734-9738$.

Rabson, A.B., D.F. Daugherty, S. Venkatesan, K.E. Boulukos, S.I. Benn, T.M. Folks, P. Fiorino, and M.A. Martin. 1985. Transcription of novel open reading frames of AIDS retrovirus during infection of lymphocytes. Science 229: 1388-1390.

Rosen, C.A., J.G. Sodroski, and W.A. Haseltine. 1985. The location of cis-acting sequences in the human T-cell leukemia virus III (HTLV-III/LAV) long terminal repeat. Cell 41: 813823.

Rosen, C.A., J.G. Sodroski, W.C. Goh, A. Dayton, J. Lippke, and W.A. Haseltine. 1986. Post-transcriptional regulation accounts for the trans-activation of the human T-lymphotropic virus type III. Nature 319: 555-559.

Rosen, C.A., E.F. Terwilliger, A.I. Dayton, J.G. Sodroski, and W.A. Haseltine. 1988. Intragenic cis-acting art gene responsive sequences of the human immunodeficiency virus. Proc. Natl. Acad. Sci. 85: 2071-2075.

Sadaie, M.R., T. Benter, and F. Wong-Staal. 1988a. Site-directed mutagenesis of two trans-regulatory genes (tat-III, trs) of HIV-1. Science 239: 910-913.

Sadaie, M.R., J. Rappaport, T. Benter, S.F. Josephs, R. Willis, and F. Wong-Staal. 1988b. Missense mutations in an infectious human immunodeficiency viral genome: Functional mapping of tat and identification of the rev splice acceptor. Proc. Natl. Acad. Sci. 85: 9224-9228.

Sodroski, J., C. Rosen, F. Wong-Staal, S.Z. Salahuddin, M. Popovic, S. Arya, R.C. Gallo, and W.A. Haseltine. 1985. Transacting transcriptional regulation of human T-cell leukemia virus type III long terminal repeat. Science 227: 171-173.

Sodroski, J., W.C. Goh, C. Rosen, A. Dayton, E. Terwillinger, and W. Haseltine. 1986. A second post-transcriptional transactivator gene required for HTLV-III replication. Nature 321: 412-417.

Strebel, K., D. Daugherty, K. Clouse, D. Cohen, T. Folks, and M.A. Martin. 1987. The HIV " $\mathrm{A}$ " (sor) gene product is essential for vinus infectivity. Nature 328: 728-731.

Terwilliger, E., R. Burghoff, R. Sia, J. Sodroski, W. Haseltine, and C. Rosen. 1988. The art gene product of human immunodeficiency virus is required for replication. J. Virol. 62: 655658.

Wright, C., B. Felber, H. Paskalis, and G. Pavlakis. 1986. Expression and characterization of the trans-activator of HTLVIII/LAV virus. Science 234: 988-992. 


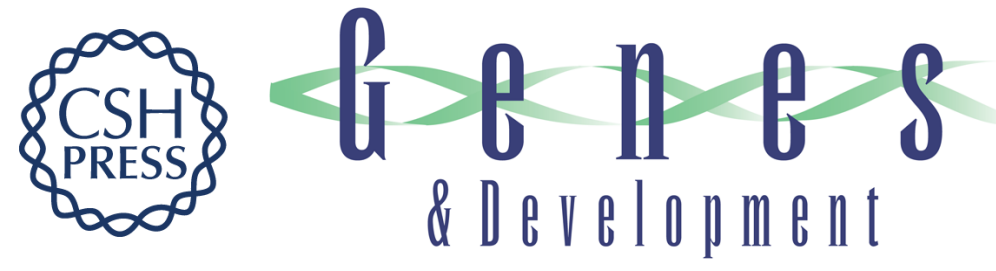

\section{Rev is necessary for translation but not cytoplasmic accumulation of HIV-1 vif, vpr, and env/vpu 2 RNAs.}

S J Arrigo and I S Chen

Genes Dev. 1991, 5:

Access the most recent version at doi:10.1101/gad.5.5.808

References This article cites 38 articles, 20 of which can be accessed free at:

http://genesdev.cshlp.org/content/5/5/808.full.html\#ref-list-1

License

Email Alerting

Service

Receive free email alerts when new articles cite this article - sign up in the box at the top right corner of the article or click here.

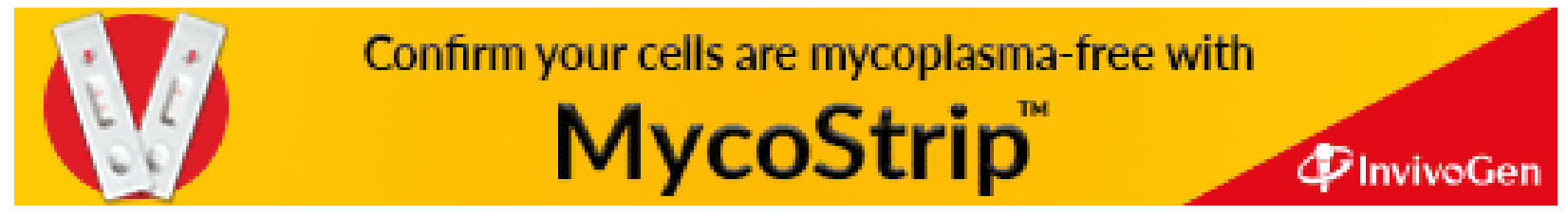

